\title{
What are the patient-held illness beliefs after a transient ischaemic attack, and do they determine secondary prevention activities: an exploratory study in a North London General Practice
}

\author{
Stania Kamara ${ }^{1}$ and Surinder Singh ${ }^{2}$ \\ ${ }^{1}$ Primary Health Care BSc, University College London, Westminster, London, UK \\ ${ }^{2}$ Senior Lecturer in General Practice, Research Department of Primary Care and Population Health, \\ University College London, Westminster, London, UK
}

\begin{abstract}
Background: A transient ischaemic attack (TIA) is a strong predictor of future stroke. Stroke is the most common cause of mortality in the United Kingdom. Management of risk factors can reduce the possibility of future strokes; however, these are often difficult to achieve optimally. Current evidence suggests that beliefs about causal attributions, severity and perceived risk of stroke may influence uptake of secondary prevention activities amongst this patient group. Aim: To explore the illness beliefs of patients about TIAs and future risk of stroke, and to determine whether these beliefs determine secondary stroke prevention activities. Method: A qualitative study comprising face-to-face, semi-structured interviews conducted in the homes of participants. Sampling was purposive and drawn from a single North London General Practice. A thematic framework analysis method was followed. Findings: Eleven participants took part in the study (aged 46-86 years, three female participants and eight male participants). Time since diagnosis ranged from 2 to 25 years. There was a commonly held belief that TIAs are 'short-lived events' associated with full recovery, whereas strokes always lead to permanent 'disability'. Only those who believed their TIAs to be 'serious' undertook activities to prevent further recurrence. Concordance with medication was the most popular prevention activity. Conclusion: The traditional medical definition of TIA and stroke do not reflect the views of patients who have had TIAs. One's perception of the severity of the initial TIA event and the risk of future stroke episodes may influence the uptake of secondary stroke prevention activities. Post TIA stroke prevention interventions should include tailored discussions focussing on the importance of the acute event and its implications for long-term health and future stroke risk.
\end{abstract}

Key words: health behaviour; ischaemic attack; patient-centred care; preventive medicine; qualitative research; stroke; transient

Received 31 January 2011; accepted 30 September 2011; first published online 24 November 2011

Correspondence to: Dr Stania Kamara, Foundation Year 2 Doctor, Medway NHS Foundation Trust, Medway Maritime Hospital, Windmill Road, Gillingham, Kent ME7 5NY, UK. Email: staniakamara@doctors.org.uk

\section{Introduction}

Stroke is a major cause of mortality and morbidity in the United Kingdom and worldwide 
(Lopez et al., 2006). A transient ischaemic attack (TIA) is a strong predictor of future stroke risk; $23 \%$ of those presenting with an ischaemic stroke will give a history of a previous TIA (Rothwell et al., 2005). There is an overwhelming evidence that the management and reduction of risk factors after a TIA reduces the risk of subsequent strokes, myocardial infarctions and other vascular events (Wolfe et al., 1996; Ringelstein and Navbavi, 2000; Rothwell et al., 2004; Hankey, 2005).

The prevention and treatment of TIA and strokes are key areas of focus for the National Health Service (Department of Health (DOH), 2009). The National Stroke Strategy (DOH, 2007) emphasises the importance of providing advice and support about lifestyle options to patients after TIAs as part of the management of vascular risk factors and stroke prevention. Despite this, current evidence suggests that concordance with secondary stroke prevention activities is difficult to achieve amongst patients after TIAs and strokes (Joseph et al., 1999; Redfern et al., 2000; Wang et al., 2006).

In comparison with the literature on stroke there are very few studies focussing on the illness beliefs and health behaviour of patients with TIAs. Some studies have shown a general lack of knowledge about TIAs and strokes amongst patients with TIAs (Johnston et al., 2003; Schneider et al., 2003). Studies about awareness of stroke risk after a TIA have found that many patients are unaware of their increased risk (Krueter and Stretcher, 1995; Samsa et al., 1997; Maasland et al., 2007; Stroebele et al., 2011). One Australian qualitative study found that patients who attribute their TIA event to an external cause - such as stress were more likely to make poor health behaviour choices, whereas those making internal causal attributions - such as a poor diet - were more likely to make positive lifestyle changes (Runions et al., 2006).

A similar study concluded that although beliefs about stroke were not predictive of health behaviour change, those who considered the event to be serious and considered themselves at risk of future strokes were more likely to make positive lifestyle changes after their TIA or stroke event (Sullivan and Waugh, 2007). Looking at the readiness to change health behaviour after a TIA event (Gillham and Endacott, 2010), enhanced secondary prevention in the form of motivational interviewing, advice and support after a TIA did not improve one's readiness to change their behaviour. Although such interventions may prove useful in increasing uptake of risk reduction activities such as exercise.

We undertook a qualitative study to explore the illness beliefs of individuals after a TIA event. We were especially interested in perceived risk of future TIA and stroke episodes and how these beliefs influenced health behaviour choices and stroke prevention activities after a TIA. Throughout this study the term 'secondary prevention' refers to lifestyle changes including smoking cessation, uptake of exercise or concordance with long-term medication use in order to prevent TIA recurrence or stroke.

\section{Methods}

Participants were chosen from the patient group of a North London General Practice (GP). Sampling was purposive and participants chosen from a range of backgrounds to ensure wide representation across age, gender, ethnicity and working status. Participants were also selected to ensure inclusion of individuals with various stroke risk factors including diabetes, hypertension and cigarette smoking. Using the search terms 'Transient Ischaemic Attack' AND 'NOT' 'Stroke', we identified 31 individuals on the GP patient database with a diagnosis of TIA and no previous ischaemic or haemorrhagic stroke event. Seven individuals were excluded from the study as they were hospitalised, residing in a nursing home, severely unwell or had an inability to communicate verbally in English at the time of interviewing. Invitation letters were sent to the remaining 24 individuals, and 13 agreed to be interviewed.

All interviews were between 45 and 60 min long and were conducted in the homes of the participants using a semi-structured schedule. Past medical history and stroke risk factor data were collected from the GP patient database, whereas smoking status was self-reported (see Table 1). All interviews were conducted, audio-recorded and transcribed by S.K., and the data were analysed by S.K. and S.S. using the Framework Analysis method outlined by Ritchie and Spencer (2000). On completing data collection, both S.K. and S.S., independently of each other, identified key ideas and recurrent themes during the process of 
Table 1 Participant characteristics

\begin{tabular}{|c|c|c|c|c|c|c|c|c|}
\hline $\begin{array}{l}\text { Patient ID no. } \\
\text { and gender }\end{array}$ & $\begin{array}{l}\text { Age } \\
\text { (years) }\end{array}$ & $\begin{array}{l}\text { Employment } \\
\text { status }\end{array}$ & $\begin{array}{l}\text { Total } \\
\text { no. of TIA } \\
\text { episodes }\end{array}$ & $\begin{array}{l}\text { No. of TIA episodes } \\
\text { which were } \\
\text { clinically strokes } \\
\text { (duration }>24 \mathrm{~h} \text { ) }\end{array}$ & $\begin{array}{l}\text { Stroke risk factors } \\
\text { (patient database } \\
\text { and self-reported) }\end{array}$ & $\begin{array}{l}\text { Causal } \\
\text { attributions }\end{array}$ & $\begin{array}{l}\text { Self-perceived } \\
\text { to be risk at of } \\
\text { future TIA and } \\
\text { stroke events? }\end{array}$ & $\begin{array}{l}\text { Secondary } \\
\text { prevention } \\
\text { activities } \\
\text { (self-reported) }\end{array}$ \\
\hline $\begin{array}{l}\text { P03M } \\
\text { Male }\end{array}$ & 82 & Retired & 1 & 0 & $\begin{array}{l}\text { Hypertension } \\
\text { Ischaemic heart disease } \\
\text { Carotid stenosis } \\
\text { Previous myocardial } \\
\text { infarction }\end{array}$ & Carotid stenosis & No & None \\
\hline $\begin{array}{l}\text { P04M } \\
\text { Male }\end{array}$ & 78 & Retired & 2 & 0 & Hypertension & $\begin{array}{l}\text { Thick blood in } \\
\text { blood vessels }\end{array}$ & No & $\begin{array}{l}\text { Medication } \\
\text { compliance }\end{array}$ \\
\hline $\begin{array}{l}\text { P05F } \\
\text { Female }\end{array}$ & 46 & Artist & 3 & 0 & $\begin{array}{l}\text { Hypertension } \\
\text { Hypercholesterolaemia }\end{array}$ & Pre-eclampsia & Yes & $\begin{array}{l}\text { Exercise } \\
\text { Diet } \\
\text { Medication } \\
\text { compliance }\end{array}$ \\
\hline $\begin{array}{l}\text { P09F } \\
\text { Female }\end{array}$ & 59 & $\begin{array}{l}\text { Self- } \\
\text { employed }\end{array}$ & 1 & 1 & Diabetes mellitus & Unknown & Yes & $\begin{array}{l}\text { Diet } \\
\text { Exercise }\end{array}$ \\
\hline $\begin{array}{l}\text { P16M } \\
\text { Male }\end{array}$ & 79 & Retired & 8 & 0 & $\begin{array}{l}\text { Atrial fibrillation } \\
\text { Hypertension } \\
\text { Smoker }\end{array}$ & $\begin{array}{l}\text { Hypertension } \\
\text { Old age }\end{array}$ & Yes & $\begin{array}{l}\text { Medication } \\
\text { compliance } \\
\text { Diet }\end{array}$ \\
\hline $\begin{array}{l}\text { P17M } \\
\text { Male }\end{array}$ & 86 & Retired & 3 & 0 & Hypertension & $\begin{array}{l}\text { Adverse life } \\
\text { events }\end{array}$ & No & None \\
\hline $\begin{array}{l}\text { P18M } \\
\text { Male }\end{array}$ & 86 & Retired & 1 & 1 & $\begin{array}{l}\text { Atrial fibrillation } \\
\text { Diabetes mellitus } \\
\text { Hypertension } \\
\text { Smoker }\end{array}$ & Unknown & No & None \\
\hline $\begin{array}{l}\text { P21M } \\
\text { Male }\end{array}$ & 68 & Retired & 2 & 0 & $\begin{array}{l}\text { Diabetes mellitus } \\
\text { Hypertension }\end{array}$ & $\begin{array}{l}\text { Self-worrier } \\
\text { Hypertension }\end{array}$ & Yes & $\begin{array}{l}\text { Low stress lifestyle } \\
\text { Exercise } \\
\text { Medication } \\
\text { compliance }\end{array}$ \\
\hline $\begin{array}{l}\text { P22F } \\
\text { Female }\end{array}$ & 68 & Retired & 1 & 0 & Hypercholesterolaemia & Unknown & Yes & $\begin{array}{l}\text { Diet } \\
\text { Medication } \\
\text { compliance }\end{array}$ \\
\hline $\begin{array}{l}\text { P24M } \\
\text { Male }\end{array}$ & 72 & Retired & 2 & 2 & $\begin{array}{l}\text { Diabetes mellitus } \\
\text { Hypertension } \\
\text { Ischaemic heart disease } \\
\text { Previous myocardial } \\
\text { infarction }\end{array}$ & $\begin{array}{l}\text { Diabetes } \\
\text { mellitus }\end{array}$ & Yes & $\begin{array}{l}\text { Medication } \\
\text { compliance }\end{array}$ \\
\hline $\begin{array}{l}\text { P25M } \\
\text { Male }\end{array}$ & 71 & Retired & 2 & 2 & $\begin{array}{l}\text { Atrial fibrillation } \\
\text { Hypertension } \\
\text { Ischaemic heart } \\
\text { disease }\end{array}$ & $\begin{array}{l}\text { Hypertension } \\
\text { Stress } \\
\text { Being taken off } \\
\text { warfarin }\end{array}$ & Yes & $\begin{array}{l}\text { Medication } \\
\text { compliance } \\
\text { Diet } \\
\text { Exercise } \\
\text { Low stress lifestyle }\end{array}$ \\
\hline
\end{tabular}


familiarisation by reading and re-reading transcripts and by reviewing field notes. The themes emerging from the interviews were initially organised loosely around ideas about the TIA event, ideas about future strokes and TIAs and thoughts about preventing such episodes. Indexing of the data involved 'cutting' and 'pasting' sections to allow sub-themes, concepts and categories to be identified. The data were then labelled using these domains and these labels allowed data grouping according to themes, thus forming charts. As part of this process, subthemes emerged and deviant cases were identified and scrutinised. To ensure reliability, after the processes of independent indexing and charting, S.S. and S.K. came together to review the key themes and sub-themes identified. Where there were differences, the original data were re-examined and a consensus reached (Pope and Mays, 2000; Bowling and Ebrahim, 2005). During the interview process S.S. and S.K. met regularly to discuss unexpected emerging ideas and review field notes. This provided the opportunity for modification of the interview schedule to allow further exploration of these concepts and ideas. The project was approved by the Barnet Primary Care Trust Research and Development Unit, with ethical approval granted by the Royal National Orthopaedic Hospital Research Ethics Committee.

\section{Findings}

Of the 24 individuals contacted, 11 patients with a diagnosis of TIA agreed to participate and were recruited to the study. Two other patients initially agreed to participate but then declined because of ill health, whereas the remaining 11 did not respond to the invitation letter or telephone communication. The non-responders and two individuals who refused were of similar characteristics in terms of age, gender and employment status compared with those included in the study.

The study participants ranged in age from 46 to 86 years old: eight participants were male, nine were retired and two of the three females were still employed. The length of time since diagnosis ranged from 2 to 25 years.

\section{Labelling, definitions and stigma}

As illustrated below, most of the participants did not immediately recognise the event as a stroke or a TIA episode, instead this label was often given when they were presented to their General Practitioner or a hospital doctor.

And I went to lay down in bed and rested and then report it to my Doctor and he told me it was a mini-stroke (Male, 79, retired; P16M)

Participants used an array of terms to name and define the episode. Some were unaware of the term 'TIA'. 'Mini-stroke' and 'minor stroke' were two terms commonly used; these terms and 'TIA' were often used interchangeably. The use of the term 'stroke' to describe the episode was more contentious; some participants used the word as it is more familiar with the public.
Probably a stroke actually, 'cos most people don't know TIAs are [...] yeah, you have to explain what a TIA is, so it's quicker everyone knows what a stroke is (Female, 46, self- employed; P05F)

Others were more cautious and made clear distinctions between what they had experienced and what they believed to be a stroke.

There was also a great deal of stigma associated with having a TIA. One participant talked about her decision to hide the TIA event from her husband as she feared of being ridiculed or misunderstood.

My immediate reaction was to hide it from

my husband because he would have told me I

was stupid, why can't you remember words?

(Female, 49, artist; P09F)

Most participants recognised a relationship between TIAs and strokes; they defined these events in their own terms, which were often not reflective of the traditional medical view. TIAs were perceived to be temporary and transient and always associated with full recovery, whereas stroke always resulted in long-term mental or physical disability. One participant considered TIAs to be less severe than strokes.

Severity, I suppose, in as much as anyone, I mean if someone says to me an older persons' had a stroke, I'm assuming it's left them with some form of disability, with some sort of long-term paralysis somewhere. Umm, TIA I suppose basically you expect to get over, I guess that's the difference. (Female, 46, self-employed; P05F) 
Another participant made similar observations:

Right, from my perspective, and this I could be totally wrong. TIA is one you recover from, there seems to be more or less complete recovery and a stroke is one where there is damage left behind (Female, 59, artist; P09F)

Participants talked of elderly friends and relatives who had experienced 'real' strokes. These episodes were often described as resulting in longterm disability or death. There was a great deal of fear reported about experiencing 'real' strokes, and participants made clear distinctions between their TIA experience and these events. This is illustrated by the experience of one participant who stated:

Next time it won't be a mini-stroke it'll be a bigger and I don't wanna be handicapped, I don't want to be a burden to my sons (Male, 71, retired; $\mathrm{P} 25 \mathrm{M}$ )

\section{Under-grading of clinical stroke episodes as TIAs}

The study criteria specifically excluded individuals who had experienced clinical strokes, that is, neurological deficits lasting more than $24 \mathrm{~h}$. However, during the interview process it became apparent that four of the eleven participants (P09F, P18M, P24M, P25M) had experienced clinical strokes. These episodes were recorded on the GP patient database as TIAs and were considered by the participants as TIAs and not strokes. One participant reported that:

It recovered over a couple of days; I got my words back over a couple of days (Female, 59, artist; P09F)

Another participant stated:

That was very, very minor actually, after about three, four days it was gone completely (Male, 71, retired; P25M)

\section{Causal attributions}

Most participants were able to identify a cause for their TIA and a wide range of reasons were proposed, from personality traits to current medical conditions; these are listed in Table 1. Most participants recognised their longstanding medical problems as contributing to their TIA. Hypertension was the most common cause identified.
Participants did not always recognise a relationship between their current health problems, which were often stroke risk factors, and their TIA event. Some individuals with conditions such as atrial fibrillation or who were smokers did not relate this to their TIA. A number of participants attributed their TIA to factors such as adverse life events, worry, stress or old-age, although these were often seen as exacerbating factors rather than the sole cause of the event. One participant who was diabetic recognised that this was a contributing factor to the TIA event.

Because the diabetic contribute to that [...] definitely is no doubt about that, they told me. Because you are diabetic that's why you get (Male, 72, retired; P24M)

Another participant considered the event to be caused by a combination of hypertension and worry.

Probably over excitement because I am also $a$ bit of a worrier, suffering from hypertension as well I don't suppose did it any good at the time. Because I suppose I get excited and cause myself to be hypertensive if you like (Male, 68, retired; P21M)

Those who identified a cause for their TIA often recognised that modifying this cause would reduce their risk of a TIA recurrence or stroke.

Yeah, if I'd had pre-eclampsia again, I'd have been in pieces thinking I'd have another stroke, without a doubt, that wasn't an option, better to look after one properly and do it properly than have two and risk myself (Female, 56, self-employed; P05F)

However, not making a causal attribution did not deter participants from undertaking secondary prevention activities.

\section{Reducing the risk of future TIA or stroke}

For most participants the TIA episode is a distant, past event with little or no impact on their current lives. Nonetheless, most of them recognised that having an episode in the past increased their risk of future TIA and stroke events and they were worried about this. Those who considered themselves at risk of future episodes expressed concerns about the potential consequences of such 
events; they were often fearful of having a severe stroke that would end their lives or leave them severely disabled. One participant talked of the potential consequences of another TIA event.

\section{I know that I had this sort of thing and you} know a mini-stroke could lead to a stroke, it can lead to a heart attack [...] and you think oh my God (Male, 68, retired; P21M)

However, these views were not shared by all participants; some did not consider their stroke to be a serious problem or, indeed, regard themselves at increased risk of future episodes. As illustrated below, some of these respondents sometimes found their other medical conditions, which were often chronic and painful, more concerning.

Arthritis is worse than mini-stroke, because they are more people suffer from arthritis [...] So mini-stroke as you see I'm all right, from arthritis very different (Male, 86, retired; $\mathrm{P} 17 \mathrm{M}$ )

Those who believed they were at risk of future events made attempts to reduce this risk. The most popular secondary stroke prevention activity was to take medication. Participants often found concordance with medication more achievable than lifestyle changes such as diet modification or exercise. One participant reported:

I am very, very particular in taking my medication because that helps me considerably and stops it [TIAs], which in fact it has done (Male, 79, retired; P16M)

Those who did not undertake secondary prevention activities were often the same participants who did not believe they were at risk of future episodes. Despite concordance with medication to control various stroke risk factors, these individuals often did not recognise this behaviour as part of stroke prevention.

\section{Discussion}

\section{Summary of findings}

This study explores the illness beliefs of a small group of patients who have experienced a TIA. A number of key beliefs were shared by the participants. First, that TIAs are short-lived episodes, always associated with full recovery, whereas stroke events always result in residual mental or physical disability. There is a discrepancy between the medical definition and the participant's explanation of TIA and stroke events. The traditional medical view focuses on the duration of the acute event, whereas for the patient the distinction is made between complete and incomplete recovery (Table 2). It is clear that participants were more concerned with the long-term impact of the TIA event, and in particular their ability to recover from it. This difference in terminology used by patients and medical professionals could lead to misunderstandings between both parties.

Second, there was a reluctance by some study participants to use the term 'stroke' to label their TIA event, although their symptoms lasted more than $24 \mathrm{~h}$. This may well be because of a lack of public awareness or possibly related to the stigma associated with the diagnosis of stroke. Patients, not surprisingly, feared the real threat of permanent disability or, in the worst-case scenario, death. A TIA was considered less threatening and more palatable.

There also seemed to be an under-grading of 'stroke' to 'TIA'. Unfortunately we did not collect any data from the General Practitioners within the

Table 2 TIA as recovery and stroke as disability

\begin{tabular}{|c|c|c|}
\hline & $\begin{array}{l}\text { Traditional medical definition } \\
\text { (Warlow et al., 2001) }\end{array}$ & Participants' explanation \\
\hline TIA & $\begin{array}{l}\text { Symptoms resolve within } 24 \mathrm{~h} \\
\text { Full recovery and no residual deficit }\end{array}$ & $\begin{array}{l}\text { Temporary and transient } \\
\text { Full recovery and no residual deficit }\end{array}$ \\
\hline Stroke & $\begin{array}{l}\text { Symptoms continue for more than } 24 \mathrm{~h} \\
\text { Varying levels of recovery and deficit possible }\end{array}$ & $\begin{array}{l}\text { Always associated with residual physical or } \\
\text { mental disability } \\
\text { Full recovery never possible }\end{array}$ \\
\hline
\end{tabular}

TIA $=$ transient ischaemic attack.

Primary Health Care Research \& Development 2012; 13: 165-174 
practice as to why this under-grading occurred, and we are unable to make any inferences as to whether this occurrence is widespread or related only to this practice population. There could be a number of explanations for this phenomenon. It is possible that after the TIA event, patients under-reported the duration of the neurological deficits to their Doctor during the initial consultation. Or it could be due to inaccuracies in recall of the duration of the TIA event during the interview process. Another explanation is that these 'true' stroke episodes (neurological deficit $>24 \mathrm{~h}$ ) were intentionally recorded on the GP patient database as TIAs and perceived by patients as such. If this was the case, it is worthy of note that the under-grading of these events was more in line with the participants' idea of TIA as always leading to recovery and stroke as disability. With this in mind, these episodes may have been under-graded by General Practitioners to reflect this view, or possibly to minimise for the patient the stigma associated with a diagnosis of stroke. This unexpected phenomenon raises questions about the usefulness and appropriateness of the terms TIA and stroke, and their definitions. There has already been some debate within medical literature about the current medical definitions of strokes and TIAs and whether these reflect our current knowledge of the nature of these conditions (Albers et al., 2002).

For many participants, their beliefs about the TIA event did influence subsequent health behaviour. Participants were more likely to take up secondary stroke prevention activities if

a) they considered the initial TIA event to be serious and concerning or

b) they considered themselves at risk of future TIA and stroke episodes.

Identifying a cause for the TIA did appear to motivate some individuals, acting as a focus for behaviour change. A potential barrier to making lifestyle change was whether the individual had other co-morbidities, for example, arthritis. These often 'competed' with the past TIA event, and in some cases the patient believed that these other conditions were more important and relevant than the TIA.

\section{Comparison with previous literature}

Several participants with conditions placing them at high risk of stroke were unaware of this.
Such lack of awareness of stroke risk has been widely reported in studies amongst the general public, as well as within both TIA and stroke patient groups (Maasland et al., 2003; Stroebele et al., 2011). In our study, there were clear differences in behaviour between those who believed their TIA to be serious and those who did not. Participants who considered it a serious event also believed that they were at risk of future TIA episodes and strokes, and made attempts to reduce this risk by undertaking a range of secondary prevention activities. This finding is supported by Sullivan and Waugh (2007); in their study, those who believed their TIA to be serious and considered themselves at risk of future strokes were more likely to make healthy lifestyle changes.

A study similar to ours (Runions et al., 2006) reported a clear relationship between the types of causal attribution made and the level of uptake of secondary prevention activities. They concluded that those patients who attribute their TIA event to an external cause, such as stress, were more likely to make poor health behaviour choices. In our study, the relationship between causal attributions and uptake of secondary prevention activities was not as apparent. Those participants who identified 'external' factors such as stress as a cause of their TIA often saw these as contributing factors rather than as the sole cause of the event. Participants who did not recognise the relationship between their personal stroke risk factors and future risk of TIA and stroke were as likely to make lifestyle changes as those who did (see Table 1). In our study, despite not recognising a relationship between causal attributions and the TIA event, participants were still aware of their increased risk of future TIA and stroke episodes and made attempts to reduce this risk.

\section{Strengths and limitations of the study}

This study has explored an area in which there is a lack of published research. Although it is the case that generalisations cannot be made, it does highlight interesting insights of how some patients regard their long-term condition in relation to their current risk. Sampling was purposive and individuals with multiple past TIA events and a wide range of stroke risk factors were recruited. Within the study group, there was a preponderance of men and those over the age of 60 years; only 
2 out of 11 were females, and only 2 out of 11 were less than 60 years old and employed. There was a high refusal rate although study participants were of similar characteristics to non-responders.

The GP from which participants were chosen is located within a predominantly White British and middle-class community in North London; all participants were of this ethnic and social group. A group with participants from a wider range of backgrounds would have been preferable. Within our study, the length of time since diagnosis ranged from 2 to 25 years with some participants experiencing multiple TIAs, this may have influenced the accuracy of event recollection. We did not collect data on the differences in health behaviour change in relation to number of previous TIA episodes or time since TIA episode.

Several steps were taken to ensure data validity and reliability. These included maintaining field notes, multiple listening of audiotapes and reflection on findings. Along with this, both authors independently analysed the data, identifying themes and ideas, which were then discussed to ensure reliability. Another step to further test reliability was the retrospective analysis of a selection of the original interviews ( 3 out of 11 ) by one of the authors, S.S., specifically in order to check the consistency of the original coding framework and its application to the data. This study was originally carried out for an intercalated BSc in Primary Health Care at University College London and as such there were major time constraints due to university defined deadlines. In view of this, although member checking was part of the original plan, regrettably this could not be carried out.

The participants in this study were overall proactive, self-directed and empowered with regard to secondary prevention, and their level of uptake of stroke prevention activities higher than expected. It is difficult to say whether this willingness to change behaviour can be attributed solely to their experiencing a TIA. It is well recognised that those from higher social groups are more likely to make healthy lifestyle choices when compared with those from lower social groups (Acheson, 1998). It is also the case that study volunteers are often more motivated and concerned about their health. Finally, no clinical data were collected either directly from participants or from the GP patient database to corroborate the participants' self-report of uptake of secondary stroke prevention activities.

\section{Clinical implications}

Patients with TIAs are an important group for secondary stroke prevention and health promotion. They not only possess significant stroke risk factors but also the opportunity for intervention to modify behaviour and reduce the risk of future TIA and stroke episodes. Our study, along with others (Runions et al., 2006; Sullivan and Waugh, 2007) demonstrate that patients do consider their risk of future stroke events and, for some, these beliefs can influence their subsequent health behaviour. However, at this point, it is not clear which aspects of these beliefs are most important in influencing decisions about the uptake of stroke prevention activities.

The key ideas identified from this study could be utilised to inform and guide discussions between patients presenting with TIAs and their clinicians, within GP or secondary care. We suggest that patients are encouraged to explore their beliefs about causal attributions, perceived severity of TIA event and future risk of stroke. Such discussions may reveal their level of awareness of the significance of the TIA event, as well as determine their readiness to make lifestyle changes. Clinicians may also find it useful to explore their patients' use and understanding of the terms 'TIA', 'mini-stroke', 'minor stroke' and 'stroke' as a way of opening dialogue about the relationship between TIAs and strokes.

It is clear that further research is required to better understand the illness beliefs of this patient group. Future studies could explore the terminology and labels used to define stroke and TIA events, as well as beliefs around future risk of stroke. The common idea of strokes always leading to disability and TIAs to recovery is one which requires further examination. The 'undergrading' and recording of clinical stroke events as TIAs was an unexpected and intriguing finding; studies to explore the prevalence of this phenomenon as well as examining the views of General Practitioners on this may prove insightful. Larger studies would make it possible to quantify the uptake of stroke prevention activities and potentially relate the degree of lifestyle change to specific illness beliefs held by patients after a TIA. Future studies should recruit participants from a number of practices with varying patient populations to determine the influence of factors such as social class or ethnic group on this topic. A prospective cohort design may give insight into illness beliefs 
and health behaviour change at the time of the TIA event, as well as during the months and years after.

\section{Acknowledgements}

We thank all the patients who shared their experiences and opinions with us, their contribution to this research is invaluable. We also thank the GP tutor who hosted S.K. during her intercalated BSc year and provided much support and encouragement. Finally, we thank the three anonymous reviewers who with great patience have provided sound advice and guidance on earlier drafts. Funding: This work was supported by the Research Department of Primary Care and Population Health, University College London. Ethical approval: Granted by the Royal National Orthopaedic Hospital Research Ethics Committee (Ref: 07/H0724/60).

\section{References}

Albers, G., Louis, R., Caplan, M., Easton, J., Fayad, P. and Mohr, J. 2002: Transient Ischaemic attack - proposal for a new definition. New England Journal of Medicine 347, 1713-16.

Acheson, D. 1998: Independent inquiry into inequalities in health report. Retrieved 17 August 2011 from http://www. archive.official-documents.co.uk/document/doh/ih/ih.html

Bowling, A. and Ebrahim, S. 2005: Handbook of research methods in health: investigation, measurement and analysis, first edition. London, UK: Open University Press.

Department of Health. 2007: National stroke strategy. Retrieved 17 August 2011 from http://www.dh.gov.uk/prod_ consum_dh/groups/dh_digitalassets/documents/digitalasset/ dh 081059 .pdf

Department of Health. 2009: The NHS operating framework for England for 2010/11. Retrieved 17 August 2011 from http://www.dh.gov.uk/en/Publicationsandstatistics/Publications/ PublicationsPolicyAndGuidance/DH_091445

Gillham, S. and Endacott, R. 2010: Impact of enhanced secondary prevention on health behaviour in patients following minor stroke and transient ischaemic attack: a randomized controlled trial. Clinical Rehabilitation 24, 822-30.

Hankey, G. 2005: Preventable stroke and stroke prevention. Journal of Thrombosis and Haemostasis 3, 1638-45.

Johnston, S., Fayad, P., Gorelick, D., Shawyder, P., van Husen, D. and Weiskopf, T. 2003: Prevalence and knowledge of transient ischaemic attack among US adults. Neurology 60, 1429-34.

Joseph, L., Babikian, V., Allwn, N. and Winter, M. 1999: Risk factor modification in stroke prevention: the experience of a stroke clinic. Stroke 30, 16-20.
Krueter, M. and Stretcher, V. 1995: Changing inaccurate perceptions of health risk: results from a randomised controlled trial. Health Psychology 14, 56-63.

Lopez, A., Mathers, C., Ezzati, M., Jamison, D. and Murray, C. 2006: Global and regional burden of disease and risk factors, 2001: systematic analysis of population health data. Lancet 367, 1747-57.

Maasland, L., Koudstaal, P., Habbema, D. and Dippel, D. 2007: Knowledge and understanding of disease process, risk factors and treatment modalities in patients with a recent TIA or minor ischemic stroke. Cerebrovascular Diseases 23, 435-40.

Pope, C. and Mays, N. 2000: Qualitative research in health care: analysing qualitative data. British Medical Journal 320, 114-16.

Redfern, J., McKevitt, C., Dundas, R., Rudd, A. and Wolfe, C.D. 2000: Behavioural risk factor prevalence and lifestyle change after stroke: a prospective study. Stroke 31, 1877-81.

Ringelstein, E. and Navbavi, D. 2000: Long-term prevention of ischaemic stroke and stroke recurrence. Thrombosis Research 98, 83-96.

Ritchie, J. and Spencer, L. 2000: Qualitative data analysis for applied policy research. In Bryman, A. and Burgess, R., editors, Analyzing qualitative data. London: Routledge, 173-94

Rothwell, P., Coull, A., Giles, M., Howard, S., Silver, L., Bull, L., Gutnikov, S., Edwards, P., Mant, D., Sackley, C., Farmer, A., Sandercock, P., Dennis, M., Warlow, C., Bamford, J. and Anslow, P. 2004: Change in stroke incidence, mortality, case-fatality, severity, and vascular risk factors in Oxfordshire, UK from 1981 to 2004 (Oxford Vascular Study). Lancet 363, 1925-33.

Rothwell, P., Coull, A., Silver, L., Fairhead, J., Giles, M., Lovelock, C., Redgrave, J., Bull, L., Welch, S., Cuthberston, F., Binney, L., Gutnikov, S., Anslow, P., Banning, A., Mant, D. and Mehta, Z. 2005: Populationbased study of event-rate, incidence, case fatality, and mortality for all acute vascular events in all arterial territories (Oxford Vascular Study). Lancet 366, 1772-83.

Runions, S., Arnaert, A. and Sourial, R. 2006: Casual attributions and health behaviour choices among stroke and transient ischaemic attack survivors. Journal of Neuroscience Nursing 38, 288-95.

Samsa, G., Cohen, S., Goldstein, L., Bonita, A., Duncan, P. and Enarson, C. 1997: Knowledge of risk among patients at increased risk for stroke. Stroke 28, 916-21.

Schneider, A., Pancioli, A., Khoury, J., Rademacher, E., Tuchfarber, A. and Miller, R. 2003: Trends in community knowledge of the warning signs and risk factors for stroke. Journal of American Medical Association 289, 343-46.

Stroebele, N., Muller-Riemenschneider, F., Nolte, C., MullerNordhorn, J., Angelina Bockelbrink, A. and Willich, S. 2011: Knowledge of risk factors, and warning signs of stroke: a systematic review from a gender perspective. International Journal of Stroke 6, 60-66. 


\section{Stania Kamara and Surinder Singh}

Sullivan, K. and Waugh, D. 2007: Toward the development of the Cerebrovascular Attitudes and Beliefs Scale (CABS): a measure of stroke-related health beliefs. Topics in Stroke Rehabilitation 14, 41-51.

Wang, YJ., Wu, D., Wang, YL., Ma, R., Wang, C. and Zhao, W. 2006: A survey on adherence to secondary ischaemic stroke prevention. Neurology Research 28, 16-20.
Warlow, C., Dennis, M., van Gijn, J., Hankey, G., Sandercock, P., Bamford, J. and Wardlaw, J. 2001: Stroke: a practical guide to management, second edition. Oxford: Blackwell Science Ltd.

Wolfe, C., Stojcevic, N. and Stewart, J. 1996: The effectiveness of measures aimed at reducing the incidence of stroke. In Wolfe, C., Rudd, T. and Beech, R., editors. Stroke services and research. London: Stroke Association, 39-86. 